ARTICLE

https://doi.org/10.1038/s41467-019-12852-9

\title{
Dilution effect of the building area on energy intensity in urban residential buildings
}

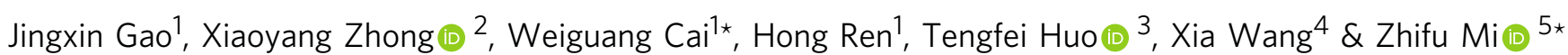

Urban residential buildings make large contributions to energy consumption. Energy consumption per square meter is most widely used to measure energy efficiency in urban residential buildings. This study aims to explore whether it is an appropriate indicator. An extended STIRPAT model was used based on the survey data from 867 households. Here we present that building area per household has a dilution effect on energy consumption per square meter. Neglecting this dilution effect leads to a significant overestimation of the effectiveness of building energy savings standards. Further analysis suggests that the peak of energy consumption per square meter in China's urban residential buildings occurred in 2012 when accounting for the dilution effect, which is 11 years later than it would have occurred without considering the dilution effect. Overall, overlooking the dilution effect may lead to misleading judgments of crucial energy-saving policy tools, as well as the ongoing trend of residential energy consumption in China.

\footnotetext{
${ }^{1}$ Chongqing University School of Management Science and Real Estate, Chongqing University, Chongqing, PR China. ${ }^{2}$ Institute of Environmental Sciences (CML), Leiden University, Einsteinweg, 2, 2333 CC Leiden, The Netherlands. ${ }^{3}$ School of Economics and Management, Hebei University of Technology, Tianjin 300401, PR China. ${ }^{4}$ School of Public Finance and Taxation, Southwestern University of Finance and Economics, Chengdu, PR China. ${ }^{5}$ The Bartlett School of Construction and Project Management, University College, London, London WC1E 7HB, UK. *email: wgcai@cqu.edu.cn; z.mi@ucl.ac.uk
} 
$\mathrm{H}$ uman activities are influencing the process of global climate change by emitting large amounts of greenhouse gases into the air, and global warming has become the most significant environmental problem facing humankind so far ${ }^{1,2}$. Approximately one-third of global greenhouse gas emissions and $40 \%$ of energy consumption is associated with the building sector ${ }^{3}$. As the largest carbon emitter, China accounts for over one-quarter of the world's total carbon emissions, and the global carbon reduction trend is highly correlated with China's emission reduction ${ }^{4}$. Although China's economic growth has entered a new normal stage, the urbanization process will undoubtedly continue after decades of vigorous development ${ }^{5}$. As a result, the number and scale of Chinese cities have increased dramatically, encouraging the rapid expansion of buildings and its attendant surging energy consumption. The urban residential building energy consumption (URBEC) has increased from 309 Million ton coal equivalent (Mtce) in 2001 to 857 Mtce in 2015 in China. At the same time, with the deepening of the industrialization process, industrial energy savings potential has been declining. Therefore, the building sector has to assume more energy-saving and emission-reduction tasks. Currently, China's building energy consumption mainly comes from industrial buildings, public buildings and residential buildings ${ }^{6}$. Although the energy consumption per square meter for urban residential buildings (URBEC) is much lower than that of public buildings, the total floor area of residential buildings in China occupies a very high proportion of the total construction area. In addition, the demand for energy consumption caused by the improvement of housing conditions is also increasing with the continuous improvement of people's living standards ${ }^{7}$. Therefore, the residential sector has a very large potential for decreasing energy consumption and environmental impact.

Improving the residential building energy efficiency plays an essential role in reducing the URBEC. Therefore, it is of great importance to measure energy efficiency effectively, which may facilitate energy conversation policy-making. Two methods are being applied extensively for the URBEC efficiency evaluation. The first method is to directly compare the URBEC of similar buildings at a project level. The other method is to employ the URBEC per square meter as the indicator of energy efficiency, an approach which is mainly used at the industry level. Due to its ease of use and relatively low cost, the URBEC per square meter has been widely applied in most studies, research reports, energy efficiency design standards, and other relevant documents issued by universities, scientific research institutes and governments ${ }^{8-10}$.

Previous literature took the URBEC per square meter as an important efficiency indicator to analyze the driving factors of energy consumption ${ }^{11-19}$, measure energy use performance ${ }^{11,14,20}$, and evaluate the effect of policy tools and make projections ${ }^{16,18,21}$. China Building Energy Use, a widely used annual report published by the Building Energy Research Center of Tsinghua University, explores the energy use status, energy-saving potential, as well as sustainable development paths in the building sector in China, taking the energy use per square meter as an efficiency index ${ }^{22}$. The national building energy saving design standard (BESD) for residential buildings and a number of local BESDs also adopt energy consumption per square meter as the criterion for judging the energy use performance of building operation ${ }^{23-26}$. In addition, the American Council for an Energy Efficient Economy (ACEEE) also evaluates the energy conservation achievements of the building sector in global regions (including China) with the indicator kilojoules per square meter.

These studies, reports, and standards play important roles in facilitating government policy-making and efforts to upgrade building performance, which directly affect the progress of energy conservation and environmental protection. Therefore, whether it is reasonable to use the URBEC per square meter as the benchmark indicator for changing energy use efficiency is critical to energy-saving work and conducting further studies. However, to date, little or no attention has been placed on the rationality of using URBEC per square meter to measure the change in building energy consumption performance.

Here, we propose the dilution effect of building area per household on URBEC per square meter. Data from 867 Chinese households were collected to validate the dilution effect based on an extended STIRPAT model we developed. In brief, the growing floor area per household reduced the URBEC per square meter because of rapid urban sprawl. In other words, the decreasing URBEC per square meter fails to represent the real change in energy use efficiency of building operation without accounting for the dilution effect. We then introduced the interaction term of the BESD and the building area per household into the model. The empirical results show that overlooking the dilution effect leads to significant overvaluation of the effectiveness of implementing BESD in residential buildings, especially those in rapidly urbanized areas. Further analysis finds that the inflection point in the China URBEC is delayed from 2001 to 2012 if the expansion of building area per household is taken into consideration. The full details of models and data sources are available in the Methods section. In addition, we also discuss why the dilution effect phenomenon happens in China, but not everywhere, and how conditions can vary among different economies.

\section{Results}

The dilution effect of the building area per household. To untangle the impacts of the expansion of the building area per household on the URBEC per square meter, a multivariate linear regression (MLR) model was employed. Based on the survey data, the coefficients of all variables except the Building Floor number passed the $10 \%$ significance test.

As shown in Fig. 1, the influence coefficients of the variables Household size $\left(x_{3}\right)$, Household income $\left(x_{4}\right)$, Number of air conditioning units $\left(x_{5}\right)$, and Number of other household appliances $\left(x_{6}\right)$ are positive, indicating that the URBEC per square meter grows in step with the household size, household income, number of air conditionings, and other household appliances. In contrast, the building floor area per household $\left(x_{1}\right)$ is the only variable negatively affecting the URBEC per square meter, and its influence coefficient is -0.450 . Thus, the URBEC per square meter will decline as the building area per household increases. In other words, the URBEC per square meter is diluted by the building area per household. Therefore, the survey data in this research validates the dilution effect.

The URBEC per household $\left(y_{2}\right)$ is the product of the URBEC per square meter $\left(y_{1}\right)$ and the building area per household $\left(x_{1}\right)$, as shown in Eq. (1).

$$
\begin{aligned}
\text { The URBEC per household }\left(y_{2}\right)= & \text { the URBEC per square meter }\left(y_{1}\right) \\
& \times \text { the building area per household }\left(x_{1}\right)
\end{aligned}
$$

To intuitively understand how strongly the URBEC per square meter is influenced by the increase of the building area per household, we further explored the impact of the building area per household on the URBEC per household. The results show that the influence coefficient of the building area per household on the URBEC per household is positive (0.133). This finding indicates that the URBEC per household increases with the expansion of the building area per household when other factors are ruled out. Based on Eq. (1), this means that when the building area per household increases and the URBEC per square meter decreases, their product also increases. In other words, the 


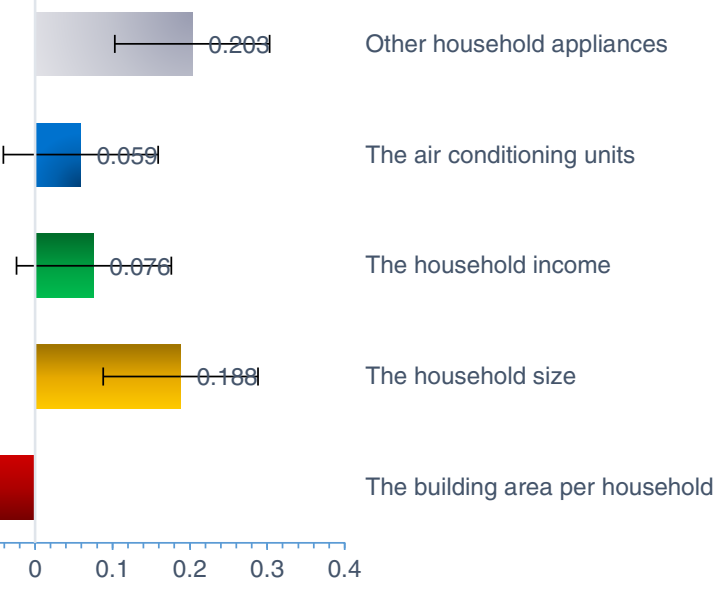

Fig. 1 The influence coefficients for the variables. The influence coefficients for household size, household income, number of air conditioning units and other household appliances on the URBEC per square meter are shown in different colors. Error bars are added in excel to donate S.D. (std. deviation)

decrease rate of the URBEC per square meter drops in the interval from 0 to the increase rate of the building area per household. The extent of this decrease depends on the gap between the rates of increase of living space and energy consumption per household (see below for further discussion). In regions where the building area per household is expanding rapidly, the dilution effect can be very significant and thus should be carefully considered.

The overestimation of the BESD effectiveness. As a widely applied policy tool, the building energy saving standard (BESD) plays a crucial role in improving the energy saving performance of urban buildings in China. However, to date, the evaluation of the BESD effectiveness has generally omitted any discussion of being influenced by the rapid expansion of building area per household. To explore how the effectiveness of BESD differs when the dilution effect is accounted for or not, indicating the impacts of the fast-growing building area per household, the interaction term of building area per household $\left(x_{1}\right)$ and BESD is introduced into the MLR model.

The results show that the influence coefficients of BESD and building area per household on the URBEC per square meter are -1.409 and -0.67 respectively, reflecting that both factors have a positive effect on reducing energy intensity (Fig. 2). However, the coefficient of the interaction term of BESD and building area per square meter is 0.309 , which shows a negative effect opposite to their single influence. With this interaction term introduced into the model, the effect coefficients of BESD and building area per square meter decreased by $21.9 \%$ and $46.1 \%$ to -1.1 and -0.361 , respectively. This finding indicates that when the increase of building area per square meter is considered, the degree of reduction in the URBEC per square meter attributed to BESD implementation decreases significantly. For those regions where floor area per household is expanding rapidly, the effectiveness of BESD adoption on energy savings should be reevaluated properly to account for the dilution effect.

The BESD moderates the dilution effect. The results also show that the adoption of the BESD in buildings can weaken the dilution effect caused by the increase in building area per household. Figure 3 demonstrates the differences in the URBEC per square meter between two groups of buildings. Buildings in group (a) adopted the BESD, while buildings in group (b) did not adopt the BESD. In both cases, the gap between the energy intensity of large-area buildings and smaller ones is obvious, which is consistent with the dilution effect. However, for buildings that meet the BESD, the reduction of the URBEC per square meter aroused by the expansion of floor area per household is less noticeable. In fact, the BESD is better implemented in more developed regions, where the pursuit of higher indoor comfort level eases the gap between the growth of the URBEC and building area per household. In general, the dilution effect could be more significant in emerging economies.

Delayed inflection point of the China URBEC. The inflection point of the URBEC per square meter is widely considered an important indicator to predict the evolution trend and the temporal peak of the URBEC in China ${ }^{27}$. As indicated by the IPAT model and Kuznets curve theory, the occurrence of the inflection point of energy intensity signifies that the urban population, economic growth, and technological level have reached a certain level, at which point further development would lead to a reduction in the increment in the energy consumption.

Here, we estimated the inflection point of the URBEC per square meter of China with and without considering the dilution effect. Figure 4 shows the change patterns of the URBEC per square meter in China from 2000 to 2016. The inflection point of URBEC intensity occurred in 2001 without considering the dilution effect. If the dilution effect is taken into account, the inflection point occurred in 2012, 11 years later than it would have occurred if the dilution effect was not considered. Thus, from 2001 to 2012, the energy intensity was still increasing (rather than decreasing) as the growth of the population, the economy, and technology increased. Only after 2012 has the URBEC per square meter truly reversed its rising trend. Since China is still undergoing a rapid expansion of urban building area, neglecting the dilution effect may cause misleading judgments about the ongoing trend of the URBEC in China.

\section{Discussion}

The past decades have witnessed a dramatic increase in the living space of urban residents, and this growth trend is expected to continue in the future. As a result, the building area per household has also been increasing, especially in many emerging economies. In the meantime, economic development contributes to the pursuit of better indoor comfort levels and living conditions in urban areas, thus leading to a higher energy demand per household. Against such a background, energy efficiency improvement is important to save energy resources and reduce the environmental impact. 


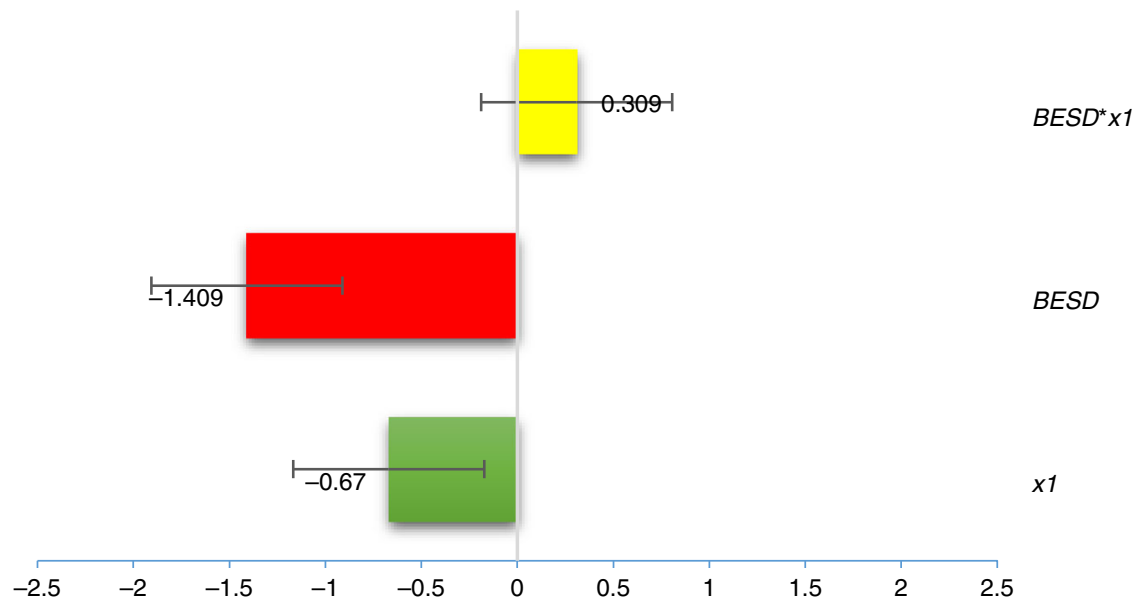

Fig. 2 The dilution effect on the building energy saving standard. The influence coefficients of BESD, the building area per household and their interaction term $\left(B E S D^{\star} x_{1}\right)$ on the URBEC per square meter
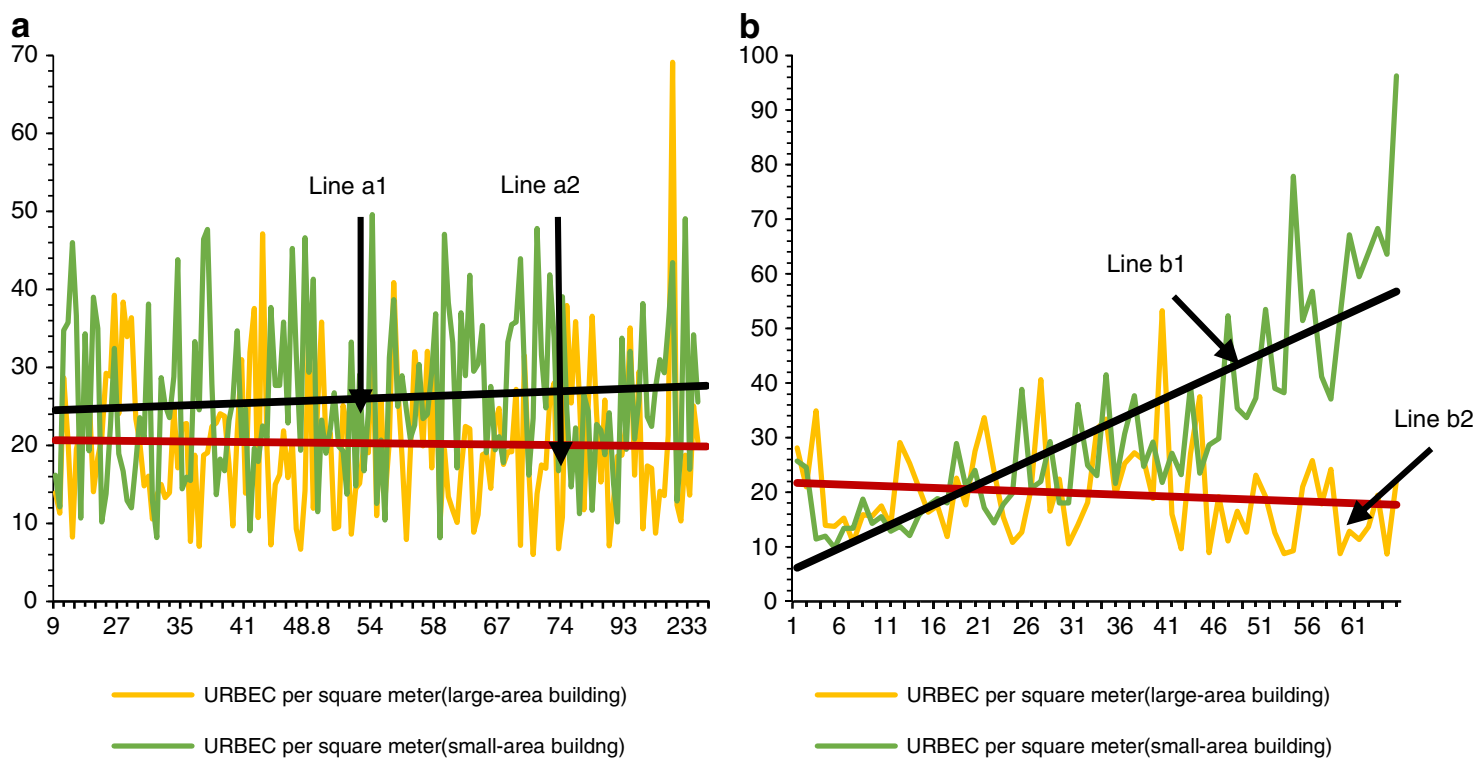

Fig. 3 Comparison of the energy intensity between small and large residential buildings. All buildings in group (a) have adopted the BESD, and all the buildings in group (b) have not adopted the BESD. Lines a1 and b1 are the trend lines of the URBEC per square meter for small residential buildings. Lines a2 and b2 are the trend lines of the URBEC per square meter for large residential buildings. The $x$-axis of figures $\mathbf{a}$ and $\mathbf{b}$ represents the difference in the building area ( $D$-value) between the matched pairs. The $y$-axis of figures $\mathbf{a}$ and $\mathbf{b}$ represents the URBEC per square meter of the matched pairs

The URBEC per square meter is widely considered as a benchmark indicator of energy intensity to measure energy use performance, estimate the effectiveness of policy tools, and understand trends. While it is obvious that the energy use per household directly affects the energy intensity, the impacts of growing building area per household on the URBEC per square meter have been overlooked. Here, we analyze the socioeconomic background of the dilution effect in China, as well as how this differs from other economies. In general, how the URBEC per square meter varies with increasing floor area per household depends on the gap between the growth rates of building area and energy use per household.

Energy consumption of residential buildings mainly result from the operation of household appliances (including heating, air conditioning, and other appliances) ${ }^{28}$. The number and the use intensity of these appliances are closely related to the number of residents and the building area ${ }^{29}$. According to the design standard of residential buildings in China, the volume of energy consumption of one building can be expressed as: $\mathrm{E}_{t}=e_{1} * A+$ $e_{2} * N . \mathrm{E}_{t}$ represents the energy consumption of the entire building at time $t$. $e_{1}$ is the energy consumption per square meter consumed by the appliances (heating, for example) associated with the floor area. $e_{2}$ is the energy consumption per capita consumed by the appliances (cooking, for example) associated with the number of residents. A denotes the total living area of the entire building. $N$ is the number of the residents living in the building. Therefore, the energy consumption per square meter of the entire building can be given as:

$$
e_{t}=\frac{e_{1} * A+e_{2} * N}{A}=e_{1}+e_{2} * N / A=e_{1}+e_{2} /(A / N)
$$

where $e_{t}$ represents the URBEC per square meter. In modern China, the household size has steadily declined since $1982^{30}$ and then gradually leveled off in recent years ${ }^{31}$. Meanwhile, there are no obvious differences in household size from family to family. In 2015, the State Health Planning Commission released China's 


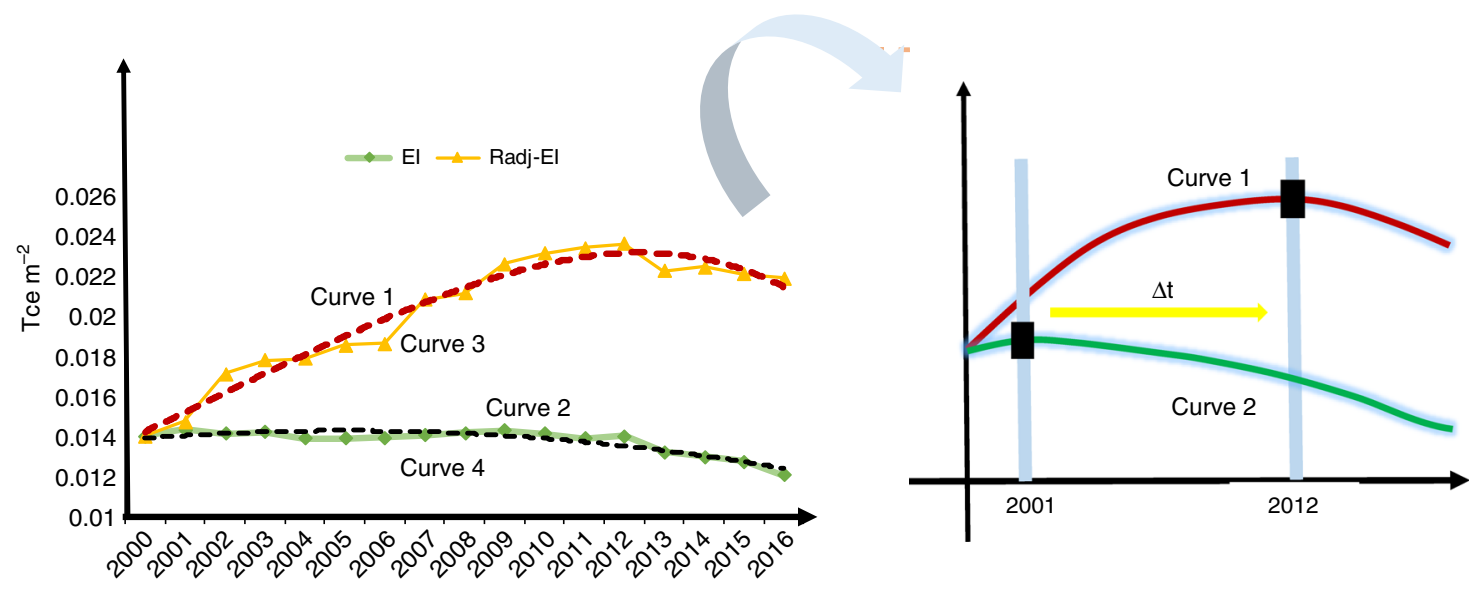

Fig. 4 Change trend and inflection point of the energy intensity. a URBEC per square meter from 2000 to 2016 in China. $\mathbf{b}$ The inflection point of the URBEC per square meter. Curve 1 refers to the trend line of the URBEC per square meter without considering the dilution effect. Curve 2 refers to the trend line of the URBEC per square meter considering the dilution effect. Curve 3 refers to the line chart of the energy intensity (URBEC per square meter) considering the dilution effect. Curve 4 refers to the line chart of the energy intensity (URBEC per square meter) without considering the dilution effect. $\Delta t$ is the delayed time between the inflection points of curve 1 and curve 2 . El represents the URBEC per square meter without considering the dilution effect and Radj-El represents the URBEC per square meter with considering the dilution effect

Household Development Report (2015). The report shows that the household size has been decreasing, and families of two and three members has become the mainstream type ${ }^{32}$. By contrast, the building area per household has shown an increasing trend since 1950. Therefore, this paper proposes two hypotheses: first, the household size has changed little in recent years; second, the building area per household has been increasing continuously ${ }^{33}$. Under the first hypothesis, the building area per capita can be expressed by formula (3).

$$
A / N=a / n
$$

$a$ is the building area per household, and $\mathrm{n}$ is the household size. The energy consumption per square meter can be expressed by formula (4).

$$
e_{t}=e_{1}+e_{2} /(a / n)
$$

For most regions, $e_{1}$ and $e_{2}$ are increasing at certain speeds depending on a number of economic, social, and environmental factors. With both the energy consumption $\left(e_{1}\right.$ and $\left.e_{2}\right)$ and the building area per household (a) growing, the change pattern of $e_{t}$ can vary significantly. In rapidly urbanized areas of China (Chongqing for example), the floor area per household has increased dramatically, overwhelming the growth pace of energy consumption $\left(e_{1}\right.$, and $\left.e_{2}\right)$. This can be attributed to the following reasons. First, an aging population and a migration from rural to urban areas squeezed living space for urban residents, leading to a rigid housing demand years ago. Second, with economic development, wealthier urban residents have a strong desire for larger living spaces, which has been nurtured by the booming real estate construction in recent years. The National Bureau of Statistics reported that floor area per household in urban China more than quintupled from $6.7 \mathrm{~m}^{2}$ in 1978 to $36.6 \mathrm{~m}^{2}$ in $2016^{34}$. Third, although people have been pursing more comfortable indoor environments, leading to higher residential energy consumption demands, the continuous improvement in building energy-saving performance moderates the upward trend of the URBEC per household.

The market-oriented reform of the Chinese real estate industry launched in the 1980s has made remarkable achievements. In the meantime, several problems have also been created in this booming industry. First, the faulty market mechanism in the real estate industry has failed to guide normal investment, resulting in a large number of speculative actions. Second, due to the imbalance between supply and demand, the market demand is huge, while the effective supply is insufficient. Moreover, the housing price-income ratio in some cities is exorbitant, thus boosting the rental market in China. As a result, both multi-house families (families owing more than one house) and renters account for a large proportion of the population in urban China, which is highly correlated with the data collection and findings of our research. In general, the reasons why people purchase more houses than they need are, to avoid summer heat or winter cold, for investment, and for earning rental income.

To illustrate how these different phenomena influence the dilution effect, a scenario analysis is conducted in this paper (see Fig. 5).

To eliminate the influences of these disturbing factors and maintain consistency of the climate zone, customs, living habits and other uncontrollable factors, we followed three criteria to collect the samples which includes that the actual residence time in the house is more than 8 months during one year; the households are owners of the houses or family tenants; and the houses are located in the main urban area of Chongqing.

Overall, our results show that the growing building area per household significantly affects the urban residential energy use per square meter in rapidly urbanized regions. Overlooking the dilution effect may lead to misleading judgments of energy conservation progress, as well as the effectiveness of sustainable policy tools. Under a $2{ }^{\circ} \mathrm{C}$ warming target, options to manage residential energy use play increasingly important roles in global carbon emission reductions. Efforts to promote residential building energy use performance must be enhanced to align with the sustainable environmental goals, and whether policy actions are truly effective highly depends upon the rationality of energy use estimation.

\section{Methods}

Extended STIRPAT model. Accompanied by the progress of industrialization, environmental problems are becoming increasingly severe. American biologists proposed the theory of technical determinism, indicating that the expansion of industrial production is the main cause of environmental problems ${ }^{35}$. Ehrlich et al. ${ }^{35,36}$ argued that the main cause of environmental problems was population growth. In follow-up studies, scholars realized that environmental issues are not shaped by a single factor. Therefore, Ellic and Holton proposed the famous IPAT 

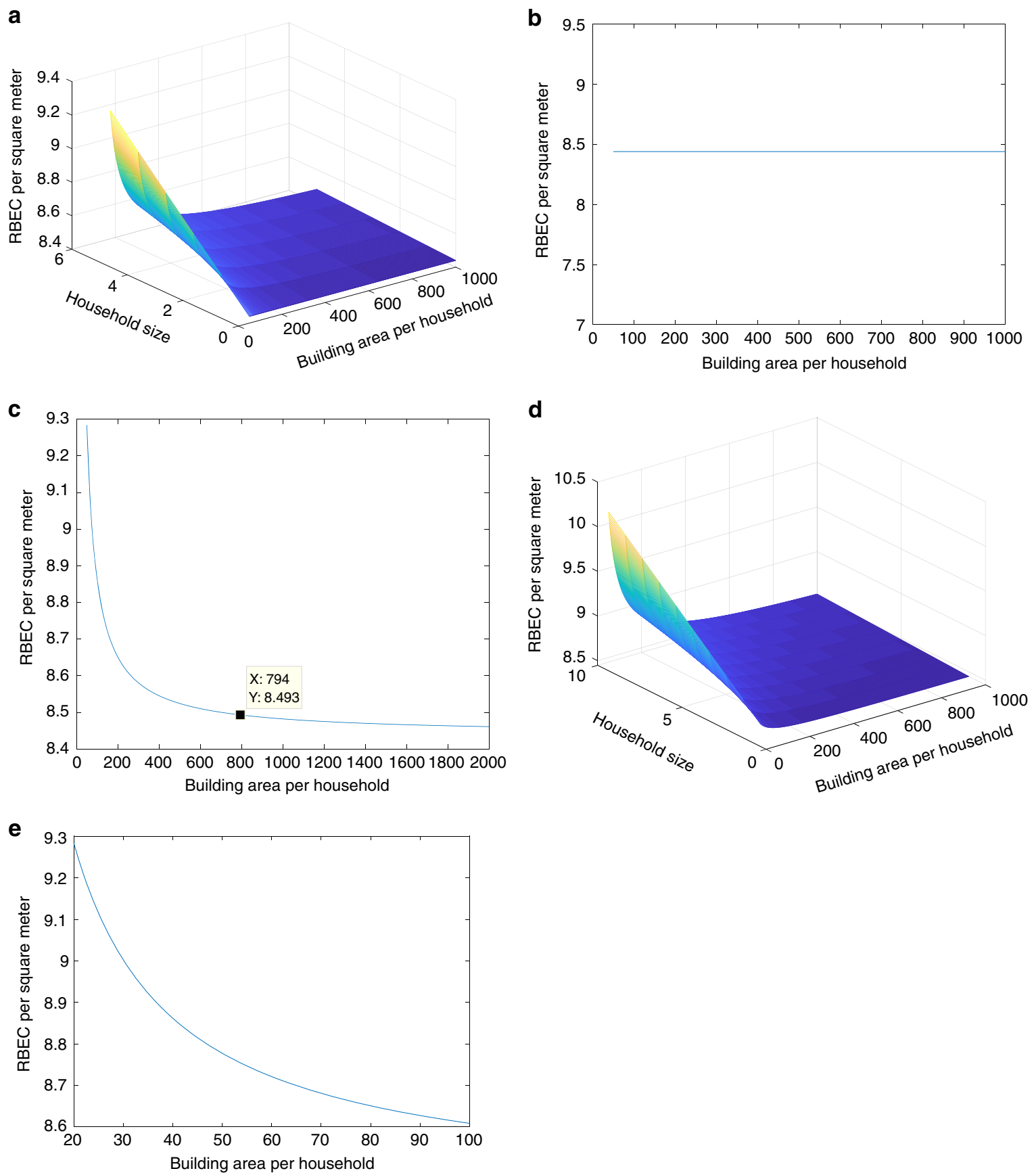

Fig. 5 The influence of different phenomena on the dilution effect. a Influence of the multi-house family (for avoiding summer heat or winter cold). The residence time for these houses is shortened greatly. According to Eq. (4), this will lead to an amplification (for large houses) or weakening (for small houses) effect on the dilution effect. $\mathbf{b}$ Influence of the multi-house family (for investment). Many houses will be left vacant, for which $e_{1}=0$ and $e_{2}$ is a constant. This leads to a similar influence on the dilution effect as the first scenario, but the amplification and weakening effects are more pronounced. c Influence of the family tenant. In this case, a family lives normally in the house and the dilution effect is not influenced. $\mathbf{d}$ Influence of the multi-person tenant. In this case, hypotheses (a) and (b) above are invalid. This leads to a weakening (for large houses) or amplification (for small houses) effect on the dilution effect. e Influence of the single-person tenant. In this case, $n=1$. This leads to an amplification (for large houses) or weakening (for small houses) effect on the dilution effect

model: ${ }^{37}$

$$
I=P \times A \times T
$$

where $I$ represents the environmental impact. $P$ denotes the population factor. $A$ is the affluence level. $T$ is the technical level. However, the premise of the IPAT model is that the effects each variable on the dependent variable are the same ${ }^{38}$. To overcome this limitation, Dietz et al ${ }^{39}$. proposed the STIRPAT model.

$$
I=\alpha P_{i t}^{\beta_{1}} A_{i t}^{\beta_{2}} T_{i t}^{\beta_{3}} e_{i t}
$$

where $\alpha$ is a constant. $\beta_{1}, \beta_{2}$, and $\beta_{3}$ are the parameters to be estimated, and $e$ represents the random error. To address the heteroscedasticity of the model, we took the natural logarithm of $I$ in formula (10) to obtain the following equation:

$$
\ln I_{i t}=\alpha+\beta_{1} \ln P_{i t}+\beta_{2} \ln A_{i t}+\beta_{3} \ln T_{i t}+e_{i t}
$$

The STIRPAT model is more extensible, and overcomes the limitations of the IPAT model, allowing variables to be added or removed according to research purposes. Considering previous literature (see Supplementary Table 1), the household size $\left(x_{3}\right)$ and the household income $\left(x_{4}\right)$ were selected as indicators of the population (variable $P$ in the IPAT model) and affluence (variable $A$ in the IPAT model), respectively. However, the technology indicator is an important, but 
difficult-to-quantify, variable. In this research, the technologies to promote the URBEC efficiency include improvements in the overall heat transfer coefficient of the building envelope, the shape coefficient of the building, the window-to-wall ratio, the heating system and so on. Therefore, the BESD of urban residential buildings, which embodies the performance of these improvement interventions, was selected as the indicator of technology level (variable T in the IPAT model). In addition, the number of floors was introduced into the STIRPAT model as variable $x_{2}$, since it significantly impacts lighting and ventilation. The number of the air conditioning units $\left(x_{5}\right)$ was particularly employed as a key variable in this model, as Chongqing is typically hot in summer and cold in winter. Other household appliances were denoted as $x_{6}$. Therefore, formulas (8) and (9) were established as follows.

$\ln y_{2}=\alpha_{0}+\alpha_{1} \ln x_{1}+\alpha_{2} \ln x_{2}+\alpha_{3} \ln x_{3}+\alpha_{4} \ln x_{4}+\alpha_{5} \ln x_{5}+\alpha_{6} \ln x_{6}+\alpha_{7} D+e_{i t}$

$\ln y_{2}=\alpha_{0}+\alpha_{1} \ln x_{1}+\alpha_{2} \ln x_{2}+\alpha_{3} \ln x_{3}+\alpha_{4} \ln x_{4}+\alpha_{5} \ln x_{5}+\alpha_{6} \ln x_{6}+\alpha_{7} D+e_{i t}$

A MLR model was then employed for parameter estimation to explore the impact of growing building area per household on the URBEC per square meter.

Impacts on BESD effectiveness. To explore how the growing building area per square meter influences the evaluation of the effectiveness of adopting BESD in residential buildings, the interaction term of BESD and $x_{1}\left(D * x_{1}\right)$ was introduced into formula (8). We then obtain formula (10) as follows.

$$
\begin{aligned}
\ln y_{1}= & \alpha+\beta_{0} D+\beta_{1} \ln x_{1}+\mu D * \ln x_{1}+\beta_{2} \ln x_{2}+\beta_{3} \ln x_{3}+\beta_{4} \ln x_{4}+\beta_{5} \ln x_{5} \\
& +\beta_{6} \ln x_{6}+e_{i t}
\end{aligned}
$$

where $\mu$ is the coefficient of the interaction term $D * x_{1}$. If the results show that $\beta_{0}$ is negative while $\mu$ is positive, then the effectiveness of adopting BESD has been overestimated with the dilution effect neglected. If both $\beta_{0}$ and $\mu$ are negative, then the impacts go in the opposite direction. With the growing building area per household considered, the real effect of BESD is represented by $\mu+\beta_{0}$.

Impacts of adopting the BESD on the dilution effect. The PSM (Propensity Score Matching) model, as a rigorous method to overcome selection bias, uses nonexperimental data or observation data to analyze the intervention effect ${ }^{40-42}$. The law of its extrapolation is as follows: if there is no A, what is the result of B? It uses the scores for sample matching and makes comparisons in order to estimate the value of the Average Treatment Effect on the Treated (ATT) ${ }^{43,44}$.

$$
\begin{gathered}
\mathrm{ATT}=\mathrm{E}\left[Y_{1}-Y_{0} \mid T=1\right] \\
\mathrm{T}= \begin{cases}1 & \text { accept the intervention } \\
0 & \text { not accept the intervention }\end{cases}
\end{gathered}
$$

In formula (11) and (12), $Y_{1}$ is the experimental group, and $Y_{0}$ is the control group. $\mathrm{T}$ is selected as the key indicator variable to identify the experimental group and the control group. Here, we take variable $x_{1}$ as the key indicator T. Then, the formula (13) is obtained.

$$
\mathrm{ATT}=\mathrm{E}\left[y_{2} \mid\left(x_{1}=1\right)\right]-\mathrm{E}\left[y_{2} \mid\left(x_{1}=0\right)\right]
$$

Because $x_{1}$ is either 0 or 1 in formula (13), we need to dichotomize the variable $x_{1}$ from a continuous variable to a $0-1$ variable. First, the data were categorized into group (a) $(\mathrm{BESD}=1)$ and group $(\mathrm{b})(\mathrm{BESD}=0)$ according to the value of the variable BESD. Second, the average values of $x_{1}$ were calculated in group (a) and group (b), respectively. The variables $x_{1}$ less than the average value were set to 0 , and those above the average value were set to 1 . Then, the dichotomized value of $x_{1}$ was stored in the $x_{11}$ variable. Finally, the data were paired by the nearest neighbor matching method.

Impacts on URBEC inflection point estimation. To eliminate the distorted influence of the dilution effect on the URBEC inflection point prediction, we introduce the area correction index (ACI) referring to the principle of the consumer price index (CPI). Given the time period concerned, the urban residential building area per capita in 2000 was selected as the base year. Therefore, the area correction index (ACI) can be expressed as

$$
\mathrm{ACI}_{i}=\frac{\mathrm{URBAPC}_{i}}{\mathrm{URBAPC}_{2000}}
$$

where $\mathrm{URBAPC}_{2000}$ and $\mathrm{URBAPC}_{i}$ denote the urban residential building area per capital in the year 2000 and year $i$, respectively. The adjusted URBEC per square meter (AURBECP) is

$$
\mathrm{AURBECP}_{i}=\mathrm{URBAPC}_{i} * \mathrm{ACI}_{i}
$$

Variable selection. A number of factors affect the URBEC per square meter, including macroeconomic factors (economy, culture, and society) and microeconomic factors ${ }^{55,46}$. Based on a review of previous literature, the key factors were classified into two types: area-related factors and residents-related factors ${ }^{47-59}$ (Supplementary Table 1).

The value of variable BESD is 1 when the energy efficiency design standard is adopted. Otherwise, its value is 0 .

$$
\mathrm{BESD}=\left\{\begin{array}{l}
1, \text { the energy efficiency design standard is adopted } \\
0, \text { the energy efficiency design standard is notadopted }
\end{array}\right.
$$

As the major source of final energy consumed by residential building operation in urban China, electricity consumption was taken to be representative of the URBEC $^{60}$. In this research, the URBEC per square meter $\left(y_{1}\right)$ and the URBEC per household $\left(y_{2}\right)$ are defined as two dependent variables.

The design standard for the energy efficiency of residential buildings (BESD) was released to improve buildings' energy use performance to reduce energy waste and carbon generation. As a major part of energy-saving efforts, the Chongqing Building Energy Conservation Association Green Building Professional Committee, the Chongqing Construction Technology Development Center, and other related departments have jointly developed the design standard for the energy efficiency of residential buildings $s^{61,62}$. Here, we select the building area per household $\left(x_{1}\right)$ as the key explanatory variable and the BESD as the auxiliary variable.

Data sources. Data for this study were collected in three ways. First, the data for the physical characteristics of the residential buildings, including name, age, and other basic information was obtained from the Chongqing Municipal Commission of Urban-Rural Development (CMCURD). Considering accessibility and convenience, multilevel random sampling techniques and the probability proportional to size (PPS) were applied to select optimal samples. Second, the data for variable values, including building area per household, number of floors, household size, household income, number of air conditioning units, and number of other appliances were collected from a survey conducted by the China Association of Building Energy Efficiency (CABEE) in 2016. A team of 40 undergraduates, 10 graduate students and $4 \mathrm{Ph}$.D. students completed this survey over almost two months. To guarantee the quality of the survey, all the team members were trained for a week in advance. During the survey, all the team members were required to record all the interviewees' telephone numbers for follow-up confirmation. The selected families met three criteria. First, the household selected had to provide the electricity billing number or the ID of the electric meter for finding the electricity consumption data from the State Grid Chongqing Electric Power Company (SGCEPC). Second, the households used the energy for consumption purposes rather than production purposes. Third, the households had been living in the building for more than one year, so that the incomparability of the energy consumption data caused by seasonal weather changes over the year can be eliminated. Third, the household electricity consumption data were collected from the SGCEPC. Based on the obtained survey data and monthly electricity consumption data for 867 households, the basic statistical characteristics of the variables are shown in Supplementary Table 2.

Collinearity test. To avoid the result deviation caused by the collinearity of variables, the variance inflation factor (VIF) was calculated. As shown in Supplementary Table 3, the VIF for all variables is between 1.02 and 1.36. The closer the VIF is to 1 , the smaller the collinearity of variables will be. Therefore, the results demonstrate that there is no collinearity among the variables selected in this paper.

\section{Data availability}

The data for the physical characteristics of the residential buildings, the household electricity consumption and variable values, including building area per household, number of floors, household size, household income, number of air conditioning units, and number of other appliances are in Supplementary data 1. The data for the PSM (Propensity Score Matching) model is in Supplementary data 2. The source data for the Fig. 3 is in Supplementary data 3 and 4 . The source data for the Fig. 4 is in Supplementary data 5. Supplementary Table 1 is the factors influencing the URBEC per square meter. Supplementary Table 2 is the statistical characteristics of the variables. Supplementary Table 3 is variance inflation factor of variables.

\section{Code availability}

All the computer code generated during this study is available from the corresponding authors and provided in the Supplementary Data 6.

Received: 23 June 2018; Accepted: 2 October 2019; Published online: 30 October 2019

\section{References}

1. Palmer, C. \& Larson, B. M. H. Should we move the whitebark pine? Assisted migration, ethics and global environmental change. Environ. Values 23, 641-662 (2014). 
2. Kaja, N. Review of built environment impacts on climate change, design strategies for reduction. Int. J. Civ. Struct. Environ. Infrastruct. Eng. Res. Dev. 2, 42-51 (2012).

3. Overpeck, J. et al. in Assessment of Climate Change in the Southwest United States: A Report Prepared for the National Climate Assessment (eds Garfin, G. et al.) 1-20 (Island Press/Center for Resource Economics, Washington DC, 2013).

4. Liu, Z. et al. Reduced carbon emission estimates from fossil fuel combustion and cement production in China. Nature 524, 335 (2015).

5. $\mathrm{Mi}, \mathrm{Z}$. et al. Chinese $\mathrm{CO}_{2}$ emission flows have reversed since the global financial crisis. Nat. Commun. 8, 1712 (2017).

6. Zhang, Y., He, C.-Q., Tang, B.-J. \& Wei, Y.-M. China's energy consumption in the building sector: a life cycle approach. Energy Build. 94, 240-251 (2015).

7. Jing, L. An empirical study of the relationship between inner Mongolia's energy and economic development. Sino Glob. Energy 15, 23-28 (2010).

8. Kavousian, A., Rajagopal, R. \& Fischer, M. Determinants of residential electricity consumption: using smart meter data to examine the effect of climate, building characteristics, appliance stock, and occupants' behavior. Energy 55, 184-194 (2013).

9. Filippín, C. Benchmarking the energy efficiency and greenhouse gases emissions of school buildings in Central Argentina. Build. Environ. 35, 407-414 (2000).

10. Birtles, A. B. \& Grigg, P. Energy efficiency of buildings: simple appraisal method. Build. Serv. Eng. Res. Technol. 18, 109-114 (1997).

11. Yao, R., Yang, Y. \& Li, B. A holistic method to assess building energy efficiency combining D-S theory and the evidential reasoning approach Energy Policy 45, 277-285 (2012).

12. Nair, G., Gustavsson, L. \& Mahapatra, K. Owners perception on the adoption of building envelope energy efficiency measures in Swedish detached houses. Appl. Energy 87, 2411-2419 (2010).

13. Ma, M., Yan, R. \& Cai, W. An extended STIRPAT model-based methodology for evaluating the driving forces affecting carbon emissions in existing public building sector: evidence from China in 2000-2015. Nat. Hazards 89, 741-756 (2017).

14. Ma, M., Yan, R. \& Cai, W. A STIRPAT model-based methodology for calculating energy savings in China's existing civil buildings from 2001 to 2015. Nat. Hazards 87, 1765-1781 (2017).

15. Ma, M., Shen, L., Ren, H., Cai, W. \& Ma, Z. How to measure carbon emission reduction in China's public building sector: retrospective decomposition analysis based on STIRPAT model in 2000-2015. Sustainability 9, 1744 (2017).

16. Li, J. \& Shui, B. A comprehensive analysis of building energy efficiency policies in China: status quo and development perspective. J. Clean. Prod. 90, 326-344 (2015).

17. Lin, B. \& Liu, H. China's building energy efficiency and urbanization. Energy Build. 86, 356-365 (2015).

18. McNeil, M. A. et al. Energy efficiency outlook in China's urban buildings sector through 2030. Energy Policy 97, 532-539 (2016).

19. Chen, H., Lee, W. L. \& Wang, X. Energy assessment of office buildings in China using China building energy codes and LEED 2.2. Energy Build. 86, 514-524 (2015).

20. Li, J. \& Colombier, M. Managing carbon emissions in China through building energy efficiency. J. Environ. Manag. 90, 2436-2447 (2009).

21. Noailly, J. Improving the energy efficiency of buildings: the impact of environmental policy on technological innovation. Energy Econ. 34, 795-806 (2012).

22. Tsinghua University Building Energy Conservation Research Center. Annual Development Report of Building Energy Conservation in China. (China Construction Industry Press, Beijing, 2016).

23. Xia, J. \& Jiang, Y. The method of determining the heating index value in the energy consumption standard of civil buildings. Constr. Sci. Technol. 14, 51-55 (2015).

24. Wu, S. Energy-saving Design Standard for Rural Residential Buildings. (China Construction Industry Press, Beijing, 2013).

25. China Academy of Architectural Sciences. Energy-saving Design Standards for Residential Buildings in Hot Summer and Cold Winter Areas. (China Construction Industry Press, Beijing, 2010)

26. Beijing Institute of Architectural Design. Technical Regulations for Energysaving Renovation of Existing Heating Residential Buildings. (China Construction Industry Press, Beijing, 2001).

27. Huo, T. et al. China's building stock estimation and energy intensity analysis. J. Clean. Prod. 207, 801-813 (2019).

28. Ouyang, J. L., Gao, J. L., Luo, X. Y., Ge, J. \& Hokao, K. Study on the relationship between household lifestyles and energy consumption of residential buildings in China. J. South China Univ. Technol. 35, 171-174 (2007).

29. Lu, J. Family change in China at the beginning of the 21st century: current situation, implication and trend. Popul. Stud. 30, 26-29 (2006).
30. Hu, Z. \& Peng, X. China's family policy in the context of family change. Popul. Stud. 36, 3-10 (2012).

31. Wang, P. China Family Development Report. (China Population Publishing House, Beijing, 2014).

32. Ge, S., Yang, D. T. \& Zhang, J. Population policies, demographic structural changes, and the Chinese household saving puzzle. Eur. Econ. Rev. 101, 181-209 (2018).

33. Ai, Z. Real estate is changing to real economy. Urban Dev. 548, 30-32 (2018)

34. Commoner, B. The Closing Circle: Nature, Man, and Technology. (Random House Inc., New York, NY, 1971).

35. Ehrlich, P. R. \& Holdren, J. P. Impact of population growth. Science 171, 1212-1217 (1971)

36. Chertow, M. R. The IPAT equation and its variants \& nspb. J. Ind. Ecol. 4, 413-429 (2010).

37. Fang, W. S., Miller, S. M. \& Yeh, C.-C. The effect of ESCOs on energy use. EnergyPolicy 51, 558-568 (2012).

38. York, R., Rosa, E. A. \& Dietz, T. STIRPAT, IPAT and ImPACT: analytic tools for unpacking the driving forces of environmental impacts. Ecol. Econ. 46, 351-365 (2003).

39. Akematsu, Y. \& Tsuji, M. Evaluation of e-health by PSM (Propensity Score Matching) method. The fifth international conference on e-health, telemedicine, and social medicine. http://www.thinkmind.org/index.php? view $=$ article\&articleid=etelemed_2013_5_40_40179 (2013).

40. Hongtao, T. et al. Does equity incentive promote enterprise innovation? -Empirical evidence from Chinese listed companies. Res. Dev. Manag. 28, 1-12 (2016).

41. Peikes, D. N., Moreno, L. \& Orzol, S. M. Propensity score matching: a note of caution for evaluators of social programs. Am. Stat. 62, 222-231 (2008).

42. Han, Y.-H., Huang, L.-X. \& Zou, J.-H. The analysis on the effects of the housing restriction policy in China's real-estate market. Econ. Manag. J. 36, 160-170 (2014).

43. Khan, M. A., Alam, M. F. \& Islam, K. J. The impact of co-management on household income and expenditure: an empirical analysis of common property fishery resource management in Bangladesh. Ocean Coast. Manag. 65, 67-78 (2012)

44. Refahi, A. H. \& Talkhabi, H. Investigating the effective factors on the reduction of energy consumption in residential buildings with green roofs. Renew. Energy 80, 595-603 (2015).

45. Shrestha, P. P. \& Kulkarni, P. Identifying factors that affect the energy consumption of residential buildings. In Construction Research Congress 2010 (American Society of Civil Engineers, Banff, Alberta, Canada, 2010).

46. Zhifeng, X. \& Yi, J. Energy consumption status and energy conservation potential analysis of large public buildings in Beijing. Heat. Vent. Air Cond. 34, 8-10 (2004).

47. Halvorsen, B. \& Larsen, B. M. Norwegian residential electricity demand-a microeconomic assessment of the growth from 1976 to 1993. Energy Policy 29, 227-236 (2001).

48. Papakostas, K. T. \& Sotiropoulos, B. A. Occupational and energy behaviour patterns in Greek residences. Energy Build. 26, 207-213 (1997).

49. Schneider, U. A. et al. Impacts of population growth, economic development, and technical change on global food production and consumption. Agric. Syst. 104, 204-215 (2011).

50. Wang, Z. H. Study on situation and development of building energy saving in China. Adv. Mater. Res. 598, 53-56 (2012).

51. Wang, X., Feng, W., Cai, W., Ren, H., Ding, C., \& Zhou, N. Do residential building energy efficiency standards reduce energy consumption in China?-A data-driven method to validate the actual performance of building energy efficiency standards. Energy Policy, 131, 82-98 (2019).

52. Wang, C. F. \& Fan, G. Q. Unscrambling the building envelope insulation technique in "Tianjin energy efficiency design standard for rural residential buildings”. Adv. Mater. Res. 805-806, 1519-1523 (2013).

53. Hong, T. A close look at the China design standard for energy efficiency of public buildings. Energy Build. 41, 426-435 (2009).

54. Wang, Q. Effects of household size on energy consumption and carbon emissions. Resour. Sci. 37, 299-307 (2015)

55. Dar, U. I., Georges, L., Sartori, I. \& Novakovic, V. Influence of occupant's behavior on heating needs and energy system performance: a case of well-insulated detached houses in cold climates. Build. Simul. 8, 499-513 (2015).

56. Copiello, S. \& Gabrielli, L. Analysis of building energy consumption through panel data: the role played by the economic drivers. Energy Build. 145, 130-143 (2017)

57. Jim, C. Y. Air-conditioning energy consumption due to green roofs with different building thermal insulation. Appl. Energy 128, 49-59 (2014).

58. Lam, T. N. T., Wan, K. K. W., Wong, S. L. \& Lam, J. C. Impact of climate change on commercial sector air conditioning energy consumption in subtropical Hong Kong. Appl. Energy 87, 2321-2327 (2010). 
59. Ong, D., Moors, T. \& Sivaraman, V. Comparison of the energy, carbon and time costs of videoconferencing and in-person meetings. Comput. Commun. 50, 86-94 (2014)

60. Deng, Y., Cao, S. \& Wei, H. Analysis on energy conservation cost of residential building in different energy codes in Chongqing. Shanxi Archit. 43, 181-182 (2017).

61. Wang, H., Bai, X., Sun, C. \& Guo, L. Analysis of energy consumption status and energy efficiency potential in large commercial buildings of Chongqing. Contam. Control Air Cond. Technol. 4, 47-50 (2005).

62. Hong, T., Li, C. \& Yan, D. Updates to the China design standard for energy efficiency in public buildings. Energy Policy 87, 187-198 (2015)

\section{Acknowledgements}

This study was supported by the National Social Science Fund of China (19BJY065), the Fundamental Research Funds for the Central Universities (No. 2019 CDJSK 03 XK 04) and National Natural Science Foundation of China (Grant No. 71902053).

\section{Author contributions}

J.G. and W.C. designed the study. J.G. performed the analysis and prepared the manuscript. J.G. and W.C. assembled input data, implemented the model and analyzed output data and results. X.W. conducted data collection and preliminary analysis. H.R. and T.H. revised the original manuscript. Z.M. and X.Z. validated modelling results and discussed the results and implications. All authors (J.G., X.Z., W.C., H.R., T.H., X.W., and Z.M.) participated in the writing of the manuscript. W.C. coordinated and supervised the project.

\section{Competing interests}

The authors declare no competing interests.

\section{Additional information}

Supplementary information is available for this paper at https://doi.org/10.1038/s41467019-12852-9.

Correspondence and requests for materials should be addressed to W.C. or Z.M.

Peer review information Nature Communications thanks the anonymous reviewer(s) for their contribution to the peer review of this work.

Reprints and permission information is available at http://www.nature.com/reprints

Publisher's note Springer Nature remains neutral with regard to jurisdictional claims in published maps and institutional affiliations.

(c) (i) Open Access This article is licensed under a Creative Common Attribution 4.0 International License, which permits use, sharing, adaptation, distribution and reproduction in any medium or format, as long as you give appropriate credit to the original author(s) and the source, provide a link to the Creative Commons license, and indicate if changes were made. The images or other third party material in this article are included in the article's Creative Commons license, unless indicated otherwise in a credit line to the material. If material is not included in the article's Creative Commons license and your intended use is not permitted by statutory regulation or exceeds the permitted use, you will need to obtain permission directly from the copyright holder. To view a copy of this license, visit http://creativecommons.org/ licenses/by/4.0/.

(C) The Author(s) 2019 